\title{
Achieved chin position after genioplasty follows the planned horizontal change better than the planned vertical change
}

\author{
Jimoh Olubanwo Agbaje a, ${ }^{*}, 1$, Yi Sun a, ${ }^{\text {, }}$ Ahmed S. Salem ${ }^{\text {a, b }}$, Zhaokai Li ${ }^{\text {, }}$ \\ Kelvin Osei Adu ${ }^{\mathrm{d}}$, Constantinus Politis ${ }^{\text {a, e }}$ \\ a OMFS-IMPATH Research Group, Department of Imaging and Pathology, Faculty of Medicine, Catholic University Leuven, Belgium \\ b Oral and Maxillofacial Surgery Department, Faculty of Dentistry, Mansoura University, Egypt \\ ${ }^{\mathrm{c}}$ Xiangya School of Medicine, Central South University, Changsha, Hunan, PR China \\ ${ }^{\mathrm{d}}$ Kwame Nkrumah University of Science \& Technology Private Mail Bag University Post Office KNUST, Kumasi, Ghana \\ e Faculty of Medicine, Hasselt University, Diepenbeek, Belgium
}

\section{A R T I C L E I N F O}

\section{Article history:}

Paper received 26 March 2017

Accepted 30 May 2017

Available online $\mathrm{xxx}$

\section{Keywords:}

Chin

Genioplasty

BSSO

Surgical planning

Postoperative result

Orthognathic surgery

\begin{abstract}
A B S T R A C T
Purpose: The soft-tissue pogonion closely follows changes of the bony pogonion, but it is unknown how often an augmented bony pogonion reaches the intended position. Here we assessed the agreement between planned surgical changes and achieved results in chin surgery.

Materials and methods: Surgical treatment was planned based on clinical examination, cast model analysis, and cephalometric image analysis. The mobile chin segment was stabilized using one chin plate. Preoperative and postoperative cephalometric X-ray images were digitized, and cephalometric tracing was performed. We calculated and analyzed the changes between the preoperative and postoperative images as well as between planned genioplasty movements and actual surgical changes in the horizontal and vertical directions.

Results: This study included 36 patients. In 34 patients, the absolute mean horizontal difference was less than $2 \mathrm{~mm}$. We found a higher range of absolute error in vertical $(0.00-5.60)$ compared to horizontal $(0.01-3.64)$ movement. There was no significant difference between the mean planned chin movement and the mean achieved position with regard to the horizontal and vertical movement ( $p=0.97$ and 0.79 , respectively).

Conclusions: The mean values for linear difference in both the horizontal and vertical directions were in line with the acceptable mean of $\leq 2 \mathrm{~mm}$ proposed in the literature.
\end{abstract}

(C) 2017 European Association for Cranio-Maxillo-Facial Surgery. Published by Elsevier Ltd. All rights reserved.

\section{Introduction}

Excessive protrusion or retrusion of the chin can occur alone or with co-existing maxillofacial deformities (Arnett and Bergman, 1993), potentially leading to functional difficulties (such as obstructive sleep apnea) and esthetic problems (Agbaje et al., 2016). Abnormal chin position can often be surgically corrected, either alone or with correction of associated maxillofacial deformities (Park et al., 1989). The literature describes many surgical options for

\footnotetext{
* Corresponding author. OMFS-IMPATH Research Group, Department of Imaging and Pathology, Faculty of Medicine, Catholic University Leuven, Kapucijnenvoer 33 , 3000, Belgium. Fax: +32 16332437.

E-mail address: joagbaje@gmail.com (J.O. Agbaje).

1 Authors with equal contribution.
}

reducing a prominent chin or augmenting a poorly projected chin. The surgical goals in such cases include the establishment of a proportionate facial height and creation of an aesthetically pleasing facial contour (Athanasiou et al., 1989; Ostler and Kiyak, 1991; Rivera et al., 2000; Williams et al., 2009).

Genioplasty with or without BSSO is the most common surgical procedure for chin correction in all planes, i.e., anteroposterior, sagittal, and vertical deficiencies (Kolokitha and Topouzelis, 2011). In addition to esthetic changes, genioplasty combined with BSSO can improve associated functional problems, such as obstructive sleep apnea, by increasing posterior airspace (Agbaje et al., 2016). Osseous genioplasty produces stable results, and reliably and consistently improves chin projection (Chan and Ducic, 2016). Although alloplastic chin implantation is a faster and easier method of augmenting a retruded chin, its use is limited by disadvantages 
that include infections, extrusion of alloplastic material, and variable bone resorption (Stalder and St, 2012; Bain and Odili, 2012; Bertossi et al., 2015). Genioplasty carries more profound predictability and better stability, ensuring a better long-term postoperative outcome (Bertossi et al., 2015).

Good postoperative results depend on the preoperative workup, including tissue analyses and surgical planning (Kusnoto, 2007). Facial harmony and symmetry are strongly influenced by the size, shape, and position of soft and hard tissues. It is critical to be able to accurately and consistently predict postoperative outcomes. At our center, we apply both Legan-Burstone analysis and the Arnett approach. To evaluate the desired vertical chin dimension, we calculate the following proportion: soft tissue subnasale-soft tissue nasion/lower incisor incisal edge-soft tissue menton. To judge the sagittal chin projection, we use the angle of facial convexity according to Legan (Powell and Humphreys, 1984; Athanasiou, 1995; Arnett and Gunson, 2004). However, the amount of vertical and sagittal change achieved through genioplasty is ultimately determined based on the surgeon's clinical judgment.

In the present study, we aimed to assess the agreement between preoperative surgical plans and the results achieved by chin surgery. To this end, we performed quantitative comparison of preoperative and postoperative cephalometric X-ray images.

\section{Materials and methods}

\subsection{Patients}

This study included patients who underwent genioplasty, with or without BSSO, or bimaxillary surgery at the Leuven University Hospital, Department of Oral and Maxillofacial Surgery, between January 2013 and December 2015. Exclusion criteria were history of syndromes or craniofacial defects, history of previous orthognathic surgery, or the use of alloplastic materials for chin augmentation. All included patients had preoperative cephalometric X-rays taken using ProMax (Planmeca, Helsinki, Finland) 3 weeks before their operation. The preoperative surgical treatment plan was determined based on clinical examination, analysis of cast models, and cephalometric image analysis (Fig. 1). This retrospective study was approved by the Medical Ethical Committee of Leuven University Hospitals (number S57587).

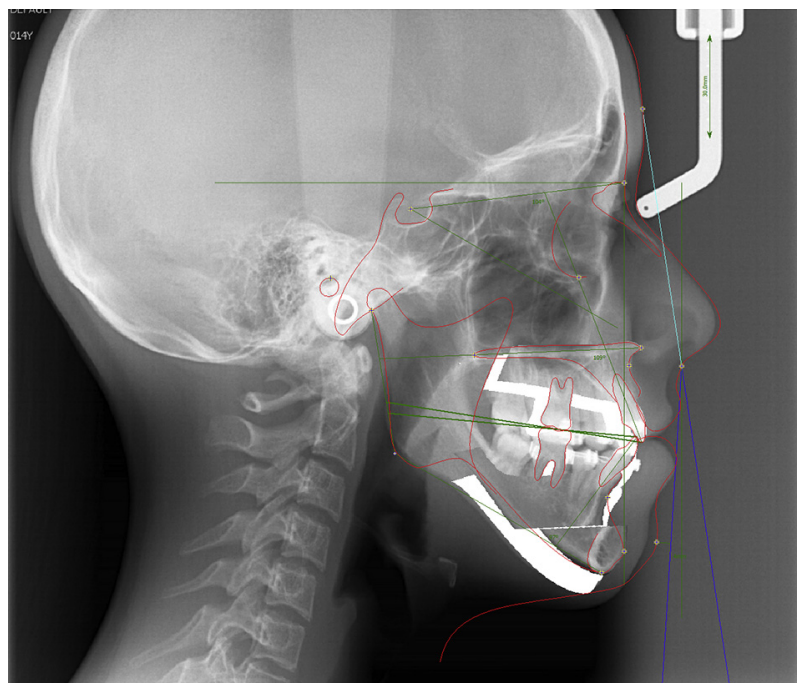

Fig. 1. Cephalometric image analysis and surgical simulation in Onyx software.

\subsection{Surgery}

All surgical procedures were performed by the same surgeon, and using the same surgical technique regardless of whether chin advancement or setback was required. The mobile chin segment was stabilized using a chin plate (KLS Martin GmbH, Freiburg, Germany) of $2,3,4,6,8$, or $10 \mathrm{~mm}$, according to the preoperative surgical treatment plan. These available chin plate sizes were considered when planning horizontal chin movement. The amount of vertical movement was determined based on the slope of the oblique osteotomy line and the amount of advancement (Fig. 2). There were three categories of planned vertical movements: $0.00 \mathrm{~mm}$ (no vertical movement); an intrusion of $\leq 4 \mathrm{~mm}$, which was realized via sliding genioplasty during an advancement procedure over an oblique osteotomy line; or an intrusion of $<4 \mathrm{~mm}$, which was performed via wedge-excision genioplasty with or without advancement.

The operative procedure began with soft tissue dissection up to the bone, followed by the drawing of three vertical reference lines using the piezzotome. Then a horizontal or triangular line was drawn with the piezzotome, defining the osteotomy lines. Symmetry was checked clinically and using calipers. Osteotomy cuts were performed using the piezzotome. The cant of the osteotomy cut was selected based on the desired vertical movement. A straight horizontal cut was made in cases of straight advancement, whereas an oblique cut was made in cases of intrusions. For an intrusion of $\leq 4 \mathrm{~mm}$, a sliding osteotomy design was chosen. For intrusion of $>4 \mathrm{~mm}$, a wedge excision was performed, together with reinsertion of the genioglossus muscle. After mobilization with a wedge osteotome, the mobile fragment was stabilized with a chin plate.

Six weeks after the operation, a second cephalometric X-ray was taken using ProMax. All cephalometric radiographs were taken by specially trained radiology technicians to ensure error-free positioning of the patient's head in the natural position, and occlusion when acquiring the lateral cephalometric X-ray image.

\subsection{Data collection and analysis}

Each cephalometric X-ray image was analyzed for hard tissue following the method of Burstone et al. (1978). Table 1 lists the cephalometric landmarks. The preoperative and postoperative cephalometric X-ray images were digitized, and cephalometric tracing was performed in Onyx software (Image Instruments, Chemnitz, Germany). The software automatically registered the postoperative cephalometric X-ray image to the preoperative cephalometric X-ray image, using an algorithm based on the correlation of image density in the unchanged part of the skull (Fig. 3).

After registration, the postoperative cephalometric X-ray image had the same coordinates as the preoperative cephalometric X-ray image (Fig. 4). In the Onyx software, a line passing through the sella and nasion points at $7^{\circ}$ clockwise rotation was defined as the $\mathrm{X}$ axis, and a line perpendicular to the $\mathrm{X}$-axis and passing through the
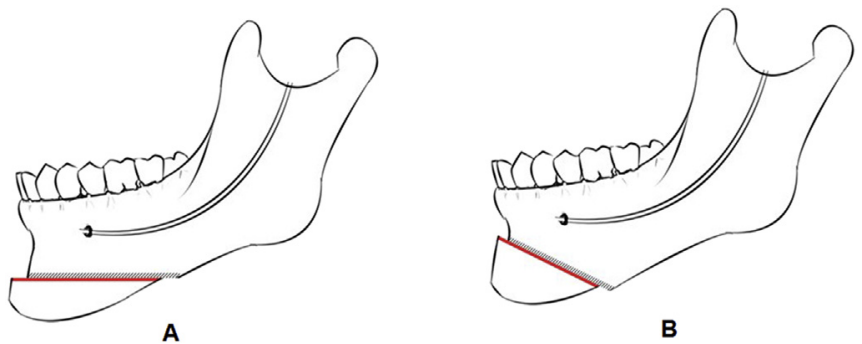

Fig. 2. Chin osteotomy line: (A) horizontal movement, (B) sliding movement. 
Table 1

Anatomical landmarks used and their definitions.

\begin{tabular}{lll}
\hline Landmark & Abbreviation & Definition \\
\hline $\begin{array}{l}\text { Sella } \\
\text { Nasion }\end{array}$ & $\mathrm{S}$ & $\begin{array}{l}\text { Center of bony contour of sella turcica } \\
\text { Most anterior point of nasofrontal } \\
\text { suture on midsagittal plane } \\
\text { Subnasal }\end{array}$ \\
Menton & Me & $\begin{array}{l}\text { upper lip in midsagittal plane } \\
\text { Most inferior midline point on } \\
\text { symphyseal outline of mandible }\end{array}$ \\
Pogonion & Pg & $\begin{array}{l}\text { Most prominent or anterior point } \\
\text { on symphysis of mandible in median plane } \\
\text { Most superior point on most anterior } \\
\text { mandibular incisor }\end{array}$ \\
Lower incisor edge L1 &
\end{tabular}

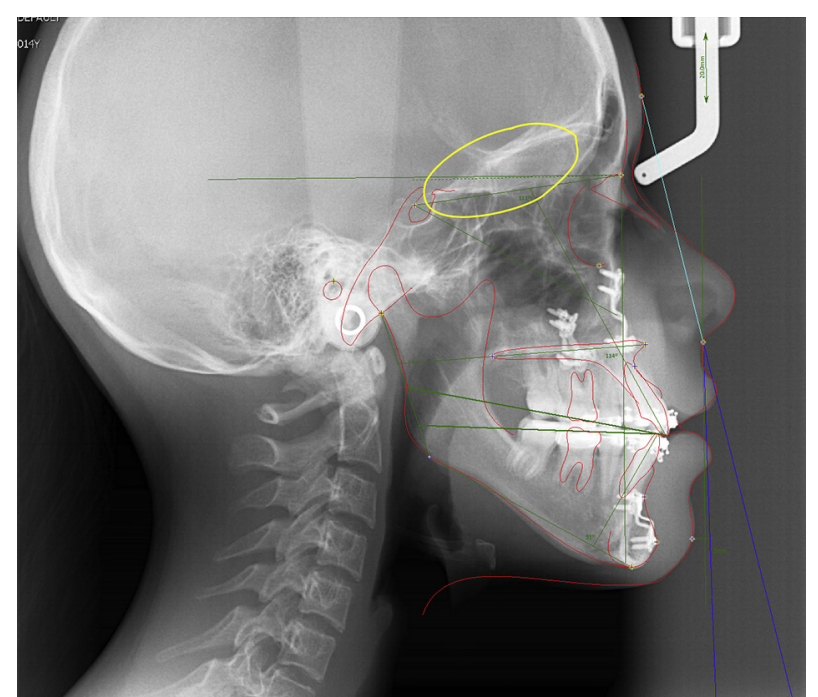

Fig. 3. An unchanged area of the skull base was manually selected (the region encircled in yellow) to register the precephalometric and postcephalometric tracings. nasion point was defined as the Y-axis (Fig. 5). The horizontal movement of the chin was calculated at the bony pogonion. The vertical change was the difference in the vertical distance from the lower incisor edge (L1) to the menton (Me) perpendicular to the mandibular plane (MP) before and after the operation.

Cephalometric tracing and measurements were performed separately by a third-year dental student and a fourth-year medical student, who were each previously trained in cephalometric tracing and measurements. Each student performed the measurement three times, with a 1-week interval between measurements. We obtained a total of six measurements of the horizontal and vertical changes of the chin between the preoperative X-rays and the X-rays taken 6 weeks after the operation. All data were exported to an Excel file for further analyses.

\subsection{Statistical analysis}

We used analysis of variance (ANOVA) to evaluate the intraassessor and inter-assessor agreement with regard to the preoperative and postoperative measurements. We used a paired $t$ test to analyze the agreement between the preoperative surgical planning and the postoperatively achieved position. Statistical calculations were performed using SPSS software, version 18.0. A $p$ value of 0.05 was considered statistically significant.

\section{Results}

Between January 2013 and December 2015, a total of 36 patients were scheduled for chin surgery ( 22 females and 14 males; mean age, $28.7 \pm 12.2$ years; age range, $16-58$ years). Among these patients, 29 underwent surgical chin advancement and 7 underwent surgical chin setback. The performed procedure was genioplasty with bimaxillary surgery in 12 cases, genioplasty with BSSO in 15 cases, genioplasty and Le fort I in 3 cases, and genioplasty alone in 6 cases. Tables 2 and 3 show the planned horizontal and vertical movements, and the corresponding numbers of patients.

The absolute difference (error) between the planned genioplasty movement and the achieved position was $1.05 \pm 0.95 \mathrm{~mm}$ in the horizontal direction (Table 2 ), and $1.66 \pm 1.39 \mathrm{~mm}$ in the vertical

Fig. 5. In the cephalometric tracing, a line passing through the sella and nasion points at $7^{\circ}$ clockwise rotation was defined as the X-axis, as described by Burstone et al. (1978). A line perpendicular to the X-axis and passing through the nasion point was defined as the Y-axis. The coordinates or corresponding landmarks and the vertical

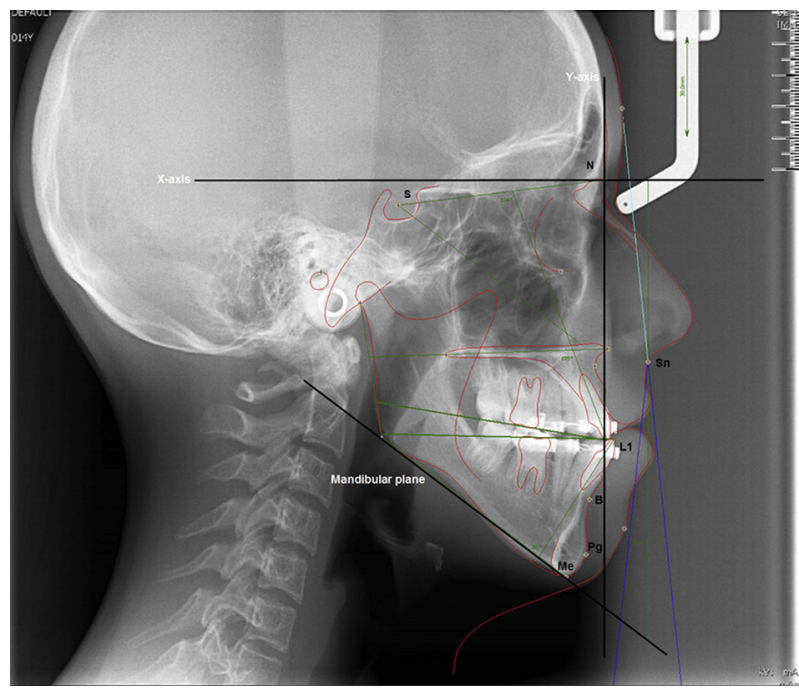
distance (1L-MP) were automatically calculated in the Onyx software.
Fig. 4. Precephalometric (black line) and postcephalometric (blue line) tracings were registered.

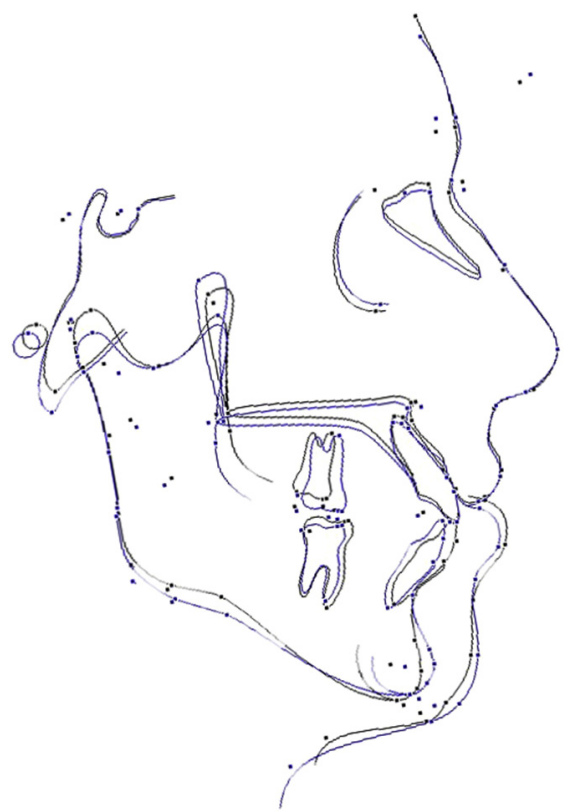

Please cite this article in press as: Agbaje JO, et al., Achieved chin position after genioplasty follows the planned horizontal change better than the planned vertical change, Journal of Cranio-Maxillo-Facial Surgery (2017), http://dx.doi.org/10.1016/j.jcms.2017.05.030 
Table 2

Accuracy of genioplasty with regard to horizontal chin movement (advancement or chin setback).

\begin{tabular}{|c|c|c|c|c|}
\hline $\begin{array}{l}\text { Planned horizontal } \\
\text { chin movement (mm) }\end{array}$ & $\begin{array}{l}\text { Actual achieved } \\
\text { movement (mm) }\end{array}$ & No. of patients & $\begin{array}{l}\text { Absolute error }(\mathrm{mm}) \\
\text { mean } \pm \mathrm{SD}\end{array}$ & $\begin{array}{l}\text { Range of absolute } \\
\text { error }(\mathrm{mm})\end{array}$ \\
\hline 2 & 3.37 & 1 & 1.37 & 1.37 \\
\hline 4 & $4.26 \pm 1.28$ & 13 & $1.03 \pm 0.75$ & $0.05-2.31$ \\
\hline 6 & $5.97 \pm 1.29$ & 13 & $0.85 \pm 0.94$ & $0.01-3.64$ \\
\hline 8 & 8.09 & 1 & 0.09 & 0.09 \\
\hline 10 & 6.03 & 1 & 3.97 & 3.97 \\
\hline-2 & -4.54 & 1 & 2.54 & 2.54 \\
\hline-4 & $-3.27 \pm 1.12$ & 6 & $0.91 \pm 0.59$ & $0.06-1.47$ \\
\hline Total & & 36 & $1.05 \pm 0.95$ & $0.01-3.64$ \\
\hline
\end{tabular}

Table 3

Accuracy of genioplasty with regard to vertical chin movement (intrusion).

\begin{tabular}{|c|c|c|c|c|}
\hline $\begin{array}{l}\text { Planned vertical chin } \\
\text { movement }(\mathrm{mm})\end{array}$ & $\begin{array}{l}\text { Actual achieved } \\
\text { movement (mm) }\end{array}$ & No. of patients & $\begin{array}{l}\text { Absolute error }(\mathrm{mm}) \\
\text { mean } \pm \mathrm{SD}\end{array}$ & $\begin{array}{l}\text { Range of absolute } \\
\text { error }(\mathrm{mm})\end{array}$ \\
\hline 0 & $2.00 \pm 1.47$ & 16 & $1.64 \pm 1.28$ & $0.00-5.0$ \\
\hline$<4$ & $1.94 \pm 1.82$ & 9 & $1.44 \pm 0.85$ & $0.04-2.90$ \\
\hline$>4$ & $5.15 \pm 2.87$ & 11 & $2.00 \pm 2.07$ & $0.01-5.60$ \\
\hline Total & $2.75 \pm 2.36$ & 36 & $1.66 \pm 1.39$ & $0.00-5.60$ \\
\hline
\end{tabular}

direction (Table 3). Figs. 6 and 7 show the planned versus achieved horizontal and vertical movements. We observed a better correlation between the planned and achieved chin movement in the horizontal movement compared to the vertical movement. The data points in the horizontal direction were better aligned along the line of best fit (Fig. 6), whereas variability was greater with regard to vertical chin movement (Fig. 7). These data suggest that horizontal movement was more accurate than vertical movement.

The ANOVA results revealed no significant difference in the measurements performed by the two assessors. We found no variability in the agreement between different measurements (i.e., the agreement was good); therefore, we did not account for the repeated assessment when performing the paired $t$ test. The paired $t$ test revealed no significant difference between the mean planned chin movement and the mean achieved position, with regard to either the horizontal or vertical movement ( $p=0.97$ and 0.79 , respectively).

\section{Discussion}

The ability to predict postoperative outcomes based on preoperative assessment and planning can help surgeons and patients with decision making. Software packages and technological tools are available to facilitate accurate prediction of proposed surgical changes and visualization of the likely end result. To achieve the planned outcome, it is critical to be able to accurately transfer the preoperative treatment plan into the operative environment. In our present study, we assessed the agreement between a preoperative surgical plan and the achieved result of chin surgery, using quantitative comparison of preoperative and postoperative cephalometric X-rays. Our results showed that the preoperatively planned movement in the horizontal direction was successfully accomplished with surgery using a chin plate.

It is believed that a horizontal and vertical difference of $<2 \mathrm{~mm}$ between the planned and achieved position is clinically

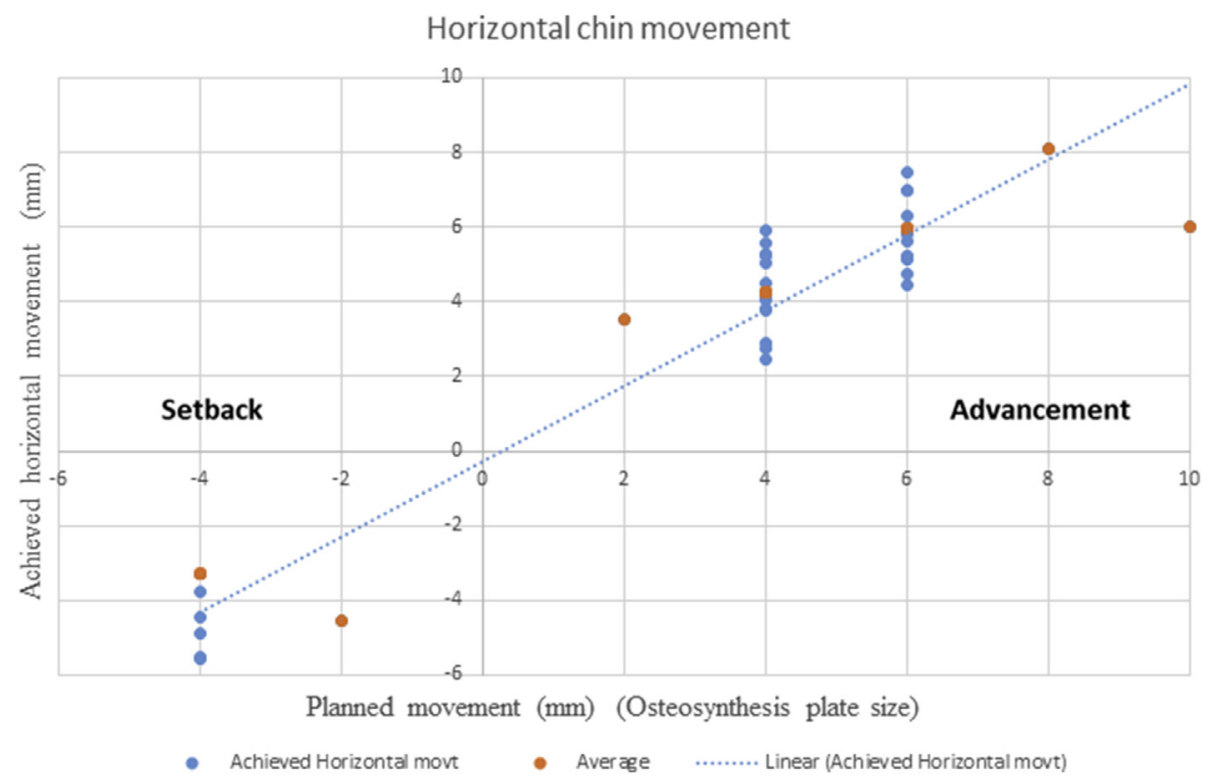

Fig. 6. Planned horizontal movements and the corresponding achieved movements for all patients. 


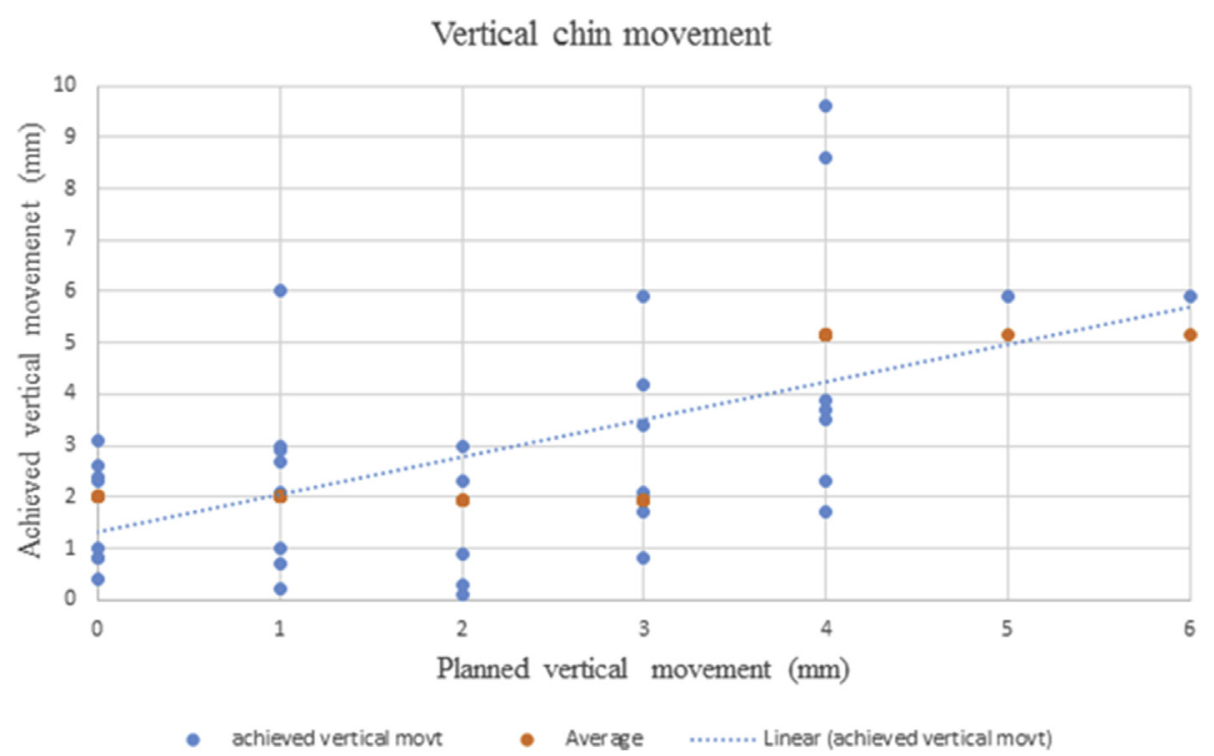

Fig. 7. Planned vertical movements and the corresponding achieved movements for all patients.

insignificant and not noticeable to the naked eye, and is thus acceptable (Hsu et al., 2013; Kang et al., 2014). In the present study, we analyzed the linear horizontal and vertical differences between the preoperative surgical plan and the achieved results, finding a mean achieved linear difference of $1.05 \pm 0.95 \mathrm{~mm}$ in the horizontal plane, and $1.66 \pm 1.39 \mathrm{~mm}$ in the vertical plane. In both directions, the mean value was within the acceptable mean linear difference of $\leq 2 \mathrm{~mm}$ established in the literature (Donatsky et al., 1992; Loh et al., 2001; Jacobson and Sarver, 2002).

Among the 36 patients included in this study, 21 were scheduled for genioplasty of $\leq 4 \mathrm{~mm}, 13$ for a $6-\mathrm{mm}$ advancement, and 2 for an advancement of $\geq 8 \mathrm{~mm}$. The degree of planned advancement or setback did not seem to affect the accuracy of the achieved result in the current study. This finding is in agreement with the results reported by Pektas et al. (2007) with regard to mandibular movement, demonstrating that the computer-generated prediction was close to the achieved surgical results, especially in the sagittal direction.

In more than $90 \%$ of our patients (34/36), the absolute mean difference between the preoperative surgical plan and the achieved result was below $2 \mathrm{~mm}$ for the horizontal movement. An absolute mean difference of $>2 \mathrm{~mm}$ was found in two patients, one patient with a planned advancement of $10 \mathrm{~mm}$ (achieved advancement of $6.03 \mathrm{~mm}$ ) and another with a planned setback of $-2 \mathrm{~mm}$ (achieved setback of $-4.54 \mathrm{~mm}$ ). With regard to vertical movement, about onethird of the patients $(11 / 36)$ showed an absolute mean difference of $>2 \mathrm{~mm}$ between the preoperative surgical plan and the achieved results. The greatest difference $(5.6 \mathrm{~mm})$ was seen in a patient with chin rotation, likely due to the fact that an asymmetrical extrusion was required. In this patient, the lateral cephalometric tracing did not accurately reflect the three-dimensional changes, resulting in a misleading reading of the two-dimensional cephalogram.

Without accounting for the direction of movement, bone measurement accuracy was better in the horizontal direction than in the vertical direction. This was evident from the smaller absolute mean error in horizontal movement $(1.05 \pm 0.95 \mathrm{~mm})$ compared to that in vertical movement $(1.66 \pm 1.39 \mathrm{~mm})$. Reduced accuracy of vertical movement is reportedly associated with some degree of rotation during fixation (Jacobson and Sarver, 2002). Our findings are in accordance with the report of Jacobson and Sarver (2002), which showed statistical differences in measurements related to the vertical placement of the posterior maxilla. Their investigation assessed the surgical accuracy of maxilla repositioning in maxillary and maxillomandibular procedures by comparing the planned outcomes with the achieved results using Dentofacial Planner software (Dentofacial Software, Toronto, Ontario, Canada).

In the literature, it is proposed that errors or inaccuracies between planned surgical movements and the achieved results are related to many factors, most of which are surgeon-related (Donatsky et al., 1992). The osteotomy angle at the osteotomy site is of paramount importance, since the steepness and direction of this osteotomy line have a directly impact on the vertical dimension when advancing or retruding the chin. In this situation, the effect is proportional to the amount of movement.

Within the limitations of this study, our present results suggest that the use of chin plate is sufficient for transferring the planned surgical movement of the chin in the horizontal direction. However, it is important to note the inherent variabilities between the planned and achieved position, even with the use of a rigid osteosynthesis plate. Overall, the planned movement was achieved after genioplasty in only a very few cases in our study.

\section{Conclusion}

Our present results confirmed the reliability of horizontal movement with a chin plate relative to the planned result. We further found that there were more frequent errors in the vertical dimension due to the difficulty of transferring the angle of osteotomy from the acetate drawing to the patient's chin. To reduce errors in sliding genioplasty with intended vertical chin movements of $>4 \mathrm{~mm}$, it may be helpful to use a surgical template to aid in producing the correct angle of osteotomy at the chin. This possibility should be further investigated.

\section{Conflict of interest}

The authors report no conflicts of interest related to this study.

\section{Acknowledgement}

The authors thank Dr. Dominique Hekner for making the illustrations. 


\section{References}

Agbaje JO, Salem AS, Lambrichts I, Braem M, Politis C: Possible association between mandibular repositioning device for sleep apnea and osseous lytic lesion with fracture of the coronoid process of the mandible: a case report. Quintessence Int 47: 141-145, 2016

Arnett GW, Bergman RT: Facial keys to orthodontic diagnosis and treatment planning. Part I. Am J Orthod Dentofacial Orthoped 103: 299-312, 1993

Arnett GW, Gunson MJ: Facial planning for orthodontists and oral surgeons. Am J Orthod Dentofacial Orthoped 126: 290-295, 2004

Athanasiou Athanasios E: Orthodontic cephalometry. London: Mosby-Wolfe, 1995

Athanasiou AE, Melsen B, Eriksen J: Concerns, motivation, and experience of orthognathic surgery patients: a retrospective study of 152 patients. Int J Adult Orthodon Orthognathic Surg 4: 47-55, 1989

Bain CJ, Odili J: Late infection of an alloplastic chin implant masquerading as squamous cell carcinoma. J Plast Reconstr Aesthetic Surg 65: e151-e152, 2012

Bertossi D, Galzignato PF, Albanese M, Botti C, Botti G, Nocini PF: Chin microgenia: a clinical comparative study. Aesthetic Plast Surg 39: 651-658, 2015

Burstone CJ, James RB, Legan H, Murphy GA, Norton LA: Cephalometrics for orthognathic surgery. J Oral Surg 36: 269-277, 1978

Chan D, Ducic Y: A simplified, reliable approach for advancement genioplasty. JAMA Facial Plast Surg 18: 114-118, 2016

Donatsky O, Hillerup S, Bjorn-Jorgensen J, Jacobsen PU: Computerized cephalometric orthognathic surgical simulation, prediction and postoperative evaluation of precision. Int J Oral Maxillofac Surg 21: 199-203, 1992

Hsu SS, Gateno J, Bell RB, Hirsch DL, Markiewicz MR, Teichgraeber JF, et al: Accuracy of a computer-aided surgical simulation protocol for orthognathic surgery: a prospective multicenter study. J Oral Maxillofac Surg 71: 128-142, 2013

Jacobson R, Sarver DM: The predictability of maxillary repositioning in LeFort 1 orthognathic surgery. Am J Orthod Dentofacial Orthoped 122: 142-154, 2002
Kang SH, Lee JW, Lim SH, Kim YH, Kim MK: Validation of mandibular genioplasty using a stereolithographic surgical guide: in vitro comparison with a manual measurement method based on preoperative surgical simulation. J Oral Maxillofac Surg 72: 2032-2042, 2014

Kolokitha OE, Topouzelis N: Cephalometric methods of prediction in orthognathic surgery. J Maxillofac Oral Surg 10: 236-245, 2011

Kusnoto B: Two-dimensional cephalometry and computerized orthognathic surgical treatment planning. Clin Plast Surg 34: 417-426, 2007

Loh S, Heng JK, Ward-Booth P, Winchester L, McDonald F: A radiographic analysis of computer prediction in conjunction with orthognathic surgery. Int J Oral Maxillofac Surg 30: 259-263, 2001

Ostler S, Kiyak HA: Treatment expectations versus outcomes among orthognathic surgery patients. Int J Adult Orthodon Orthognathic Surg 6: 247-255, 1991

Park HS, Ellis E, Fonseca RJ, Reynolds ST, Mayo KH: A retrospective study of advancement genioplasty. Oral Surg Oral Med Oral Pathol 67: 481-489, 1989

Pektas ZO, Kircelli BH, Cilasun U, Uckan S: The accuracy of computer-assisted surgical planning in soft tissue prediction following orthognathic surgery. Int J Med Robot 3: 64-71, 2007

Powell N, Humphreys B: Proportions of the aesthetic face, New York. New York: Thieme-Stratton, 1984

Rivera SM, Hatch JP, Dolce C, Bays RA, Van Sickels JE, Rugh JD: Patients' own reasons and patient-perceived recommendations for orthognathic surgery. Am J Orthod Dentofacial Orthoped 118: 134-141, 2000

Stalder MW, St Hilaire H : Immediate osseous genioplasty with Kirschner wire fixation for revision of infected alloplastic chin implant. J Craniofac Surg 23: e446-e447, 2012

Williams DM, Bentley R, Cobourne MT, Gibilaro A, Good S, Huppa C, et al: Psychological characteristics of women who require orthognathic surgery: comparison with untreated controls. Br J Oral Maxillofac Surg 47: 191-195, 2009 